that lowly stage of development, had reached any part of the American Continent. On the other hand, the idea that a satellite approached the earth and disintegrated, and that the moon was 'captured', all in Pleistocene times, is unlikely to commend itself to men of science. In view of the startling contradiction between Mr. Bellamy's conjectures and the geological time-scale, it is lost labour to follow him through the tortuous paths of his interpretation of the carvings on the Tiahuanaco gateway. This has given rise to divers interpretations-it has even been claimed that it has something to do with the Old Testament-but there is no reason whatever why it should have been a calendar.

This book first appeared in 1943, and it was reprinted in 1944. That there should now be a "new revised and augmented edition", little altered except for a six-month shift in certain signs and the addition of twenty-seven pages of astronomical explanation by another author, provokes the suggestion that its vogue may be due to the hardness of the times which drives men to seek escape in fantasy.

G. H. S. BushNeLL

\section{EVOLUTION ON GALAPAGOS}

\section{Darwin's Finches}

By David Lack. Pp. $\mathrm{x}+208+9$ plates. (Cambridge: At the University Press, 1947.) 21s. net.

T HE theories of Darwin, and particularly those propounded in the "Origin of Species", are sub. jects of evergreen interest both to laymen and to biologists, and it is constantly worth while to examine and re-examine them in the light of the newest knowledge. To-day it can be said that they have stood the test of years of antagonistic criticism and of more than a generation of precise biological research, and have re-emerged so triumphantly that Prof. R. A. Fisher has recently spoken of a renaissance of Darwinism. It is therefore of special interest to read Mr. Lack's account of the latest expedition to what is perhaps the most important region visited by Darwin, the Galapagos Islands, and to learn more of the peculiar fauna of that place. What Darwin himself once said is still true: "The natural history of these islands is eminently curious, and well deserves attention".

The Islands are oceanic, and their colonization by land animals appears to have been haphazard and of rare occurrence. To-day the main ecological niches are fully occupied, but by most unusual species. The present account concerns in particular the four genera and fourteen species of birds which have become known as Darwin's finches. It is presumed that they have all evolved from a common stock, a small group of immigrants from the American mainland, and that some of them, experiencing no competition but their own from that time onwards, have undergone unique modifications of structure and habit. Some of them, the ground finches, retained the seed-eating habit, but others, the tree finches, became insectivorous. Of the whole series, the most extraordinary are the woodpecker finch and the warbler finch. Had the niches now occupied by thesp two birds been already filled by a true woodpecker and a true warbler, it is suggested that such development could never have taken place.

The first lesson which the Islands teach is the great variety which can develop in a small virgin country from a severely restricted beginning, a lesson which is repeated there by many other animals and by the plants. A second is the paramount importance of geographical isolation for species formation. Not only has it been necessary that the colonists should be cut off from their parent stock, but the theory is also advanced that each of the various finch species must have arisen in the isolation of one or other of the Islands and later extended its range. To-day, where they meet, the species persist only because they have come to occupy different ecological niches, and this in turn must have tended to increase their specialization. In contrast, the only one of Darwin's finches which is present on Cocos Island has remained a single species. The situation of Cocos ensures almost complete isolation from the mainland, but being a single small island it offers no chances of isolation within its borders.

Mr. Lack's restatement and development of the problem of Darwin's finches is admirably done. The material summarized, the reviews which are given of past and present theories, as well as the individual views expressed by the author, are all highly stimulating and valuable, and there is an extensive biblio. graphy. The style is pleasant, the printing is excellent, and although the photographs are not up to presentday standards, the illustrations are adequate. It is a book which will be of great interest to all those, amateur and professional, who are intrigued by the problems of the origin of species.

\section{W. S. BurLough}

\section{INTRODUCTORY BIOLOGY}

\section{Biology for Medical Students}

By C. C. Hentschel and Dr. W. R. Ivimey Cook. Pp. xii +752 . (London, New York and Toronto : Longmans, Green and Co., Ltd., 1947.) 25s. net.

$\mathrm{N}$ the fourth edition of this widely used text-book the authors have taken the opportunity of considerable revisions of both the text and the illustrations. This applies particularly, so far as the text is concerned, to the botanical part; fewer changes and additions have been made in the zoological section, though there, too, the alterations are extensive.

The botanical part of this text-book has now grown to a well-rounded introduction to botany, which in scope might indeed be of use to a first-year science student; plant physiology has been extensively treated, and it was the aim of the authors to lay in this way the foundations for a later study of human physiology. The zoological part covers fully the requirements of the first-year medical student.

Criticism concerns chiefly the illustrations. Though a great number of the photographs are excellent, the quality of the diagrams varies considerably. Illustrations of the same organ in the three vertebrate types under discussion (for example, the inner ear, Figs. 255, 277 and 305, or the heart, Figs. 240, 267, 293 and 294) are not comparable and make a comparative appreciation by the student very difficult. Some of the drawings (for example, Fig. 268 or Fig. 300) are reduced too much and the many labelled details can only cause confusion; and the student will find some drawings of the chick's embryology very difficult to understand.

But in spite of these blemishes the new edition will continue to be a useful guide to the medical student in his first-year work.
A. S. 